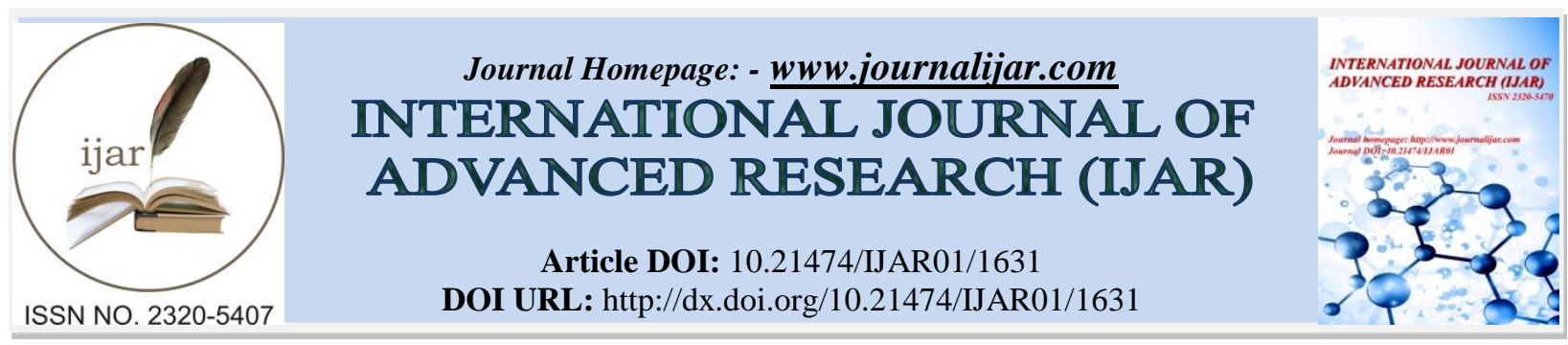

RESEARCH ARTICLE

\title{
GC-MS ANALYSIS AND ANTIMICROBIAL ACTIVITY OF SUDANESE CYPERUS ESCULENTUS (CYPERACEAE ) FIXED OIL.
}

\author{
Abdel Karim $\mathbf{M}^{1, *}$ and Fath El-Rahman $\mathrm{A}^{2}$. \\ 1. Sudan University of Science and Technology, Faculty of Science, Dept. of Chemistry. \\ 2. Omdurman Islamic University, Faculty of Education, Dept. of Chemistry.
}

\section{Manuscript Info}

Manuscript History

Received: 16 July 2016

Final Accepted: 13 August 2016

Published: September 2016

Key words:-

Cyperus esculentus, Fixed oil, GC-MS, Antimicrobial activity

\section{Abstract}

The present study was designed to investigate the chemical constituents of Cyperus esculentus seed oil and to evaluate its potential antimicrobial activity. 21 components were detected by GCMS analysis. Major constituents are: 9-octadecenoic acid (46.24\%), hexadecanoic acid(19.27\%), 9,12-octadecadienoic acid(13.62\%), and methyl stearate $(10.88 \%)$. Butylated hydroxytoluene, a potent antioxidant, was detected as a minor constituent $(0.10 \%)$. The antibacterial activity of the oil was evaluated via cup plate agar diffusion assay against six standard human pathogens(Gram positive: Staphylococcus aureus and Bacillus subtilis; Gram negative : Escherichia coli and Pseudomonasa aeruginosa and the fungi Candida albicans and Aspergillus niger) . The oil showed different antimicrobial responses against test organisms. It gave significant activity against the fungus :Candida albicans and partial activity against Staphylococcus aureus. It seems that the oil is a lead for further optimization.

Copy Right, IJAR, 2016,. All rights reserved.

\section{Introduction:-}

Cyperus esculentus is a grass- like plant of the family Cyperaceae (Sedge family) which is widely distributed in many north temperature locations within south Europe as its probable origin (Mason, 2005). Tiger nut(Cyperus esculentus) is not really a nut but a small tuber, first discovered some 4000 years ago in ancient Egypt and is cultivated today in China, Spain and West Africa . Cyperus esculentus "tiger nut" is also known as chufa, earth nut, yellow nut sedge, groundnut, rush nut, and edible galingale (Oderinde and Tairu,1988). The plant develops as a series of shoots, bulbs and stem tubers connected by brown wiry rhizomes which are strengthened by lignification of the inner cortex. Tubers are small, 1-2 cm in diameter, and are borne at intervals along the rhizomes. (Garg,1967).

Along with a high-energy content (starch, fats, sugars and proteins), the plant is rich in minerals such as phosphorous and potassium and in vitamins E, C, soluble glucose and oleic acid. Typically, 100g tiger nuts contain $386 \mathrm{kcal}(1635 \mathrm{~kJ})$ as :7\% proteins, $26 \%$ fats (oils), $31 \%$ starch, $21 \%$ glucose. It contain $26 \%$ fibre of which $14 \%$ is non-soluble. Cyperus esculentus underground tubers are considered as an important food for waterfowl ( McAfee,1939) and sand hill cranes on wintering areas (Guthery, 1976).

Cyperus esculentus, an underutilized crop, was reported to be high in dietary fibre content, which could be effective in the treatment and prevention of many diseases including colon cancer, coronary hearth diseases, obesity, diabetes 
and gastrointestinal disorders (Anderson et.al. 1994). Tiger nut has also been reported to be used in the treatment of flatulence, indigestion, diarrhea, dysentery, and excessive thirst ( Chevallier,1996). They are also used in Brazil for the treatment fever (De Abreu Matos ,2008) and in loosing weight (Borges et.al. ,2008).

\section{Materials and Methods:-}

Plant material:-

Tubers of Cyperus esculentus were purchased from the local market - Omdurman, Sudan. The plant was kindly authenticated by Institute of Aromatic and Medicinal Plants- Khartoum ,Sudan.

\section{Instruments:-}

A Shimadzo GC-MS-QP2010 Ultra instrument with a RTX-5MS column (30m,length ; 0.25mm diameter ; $0.25 \mu \mathrm{m}$, thickness) was used for GC-MS analysis .

Test organisms:-

Cyperus esculentus oil was screened for antibacterial and antifungal activities using the standard microorganisms shown in Table(1).

Table 1:- Test organisms.

\begin{tabular}{|l|l|l|}
\hline Ser. No & Microorganism & Type \\
\hline 1 & Bacillus subtilis & G+ve \\
\hline 2 & Staphylococcus aureus & G+ve \\
\hline 3 & Pseudomonas aeroginosa & G-ve \\
\hline 4 & Escherichia coli & G-ve \\
\hline 5 & Aspergillus niger & fungi \\
\hline 6 & Candida albicans & fungi \\
\hline
\end{tabular}

\section{Methods:-}

Extraction of oil from Cyperus esculentus

Dry-powdered tubers of Cyperus esculentus $(200 \mathrm{~g}$ ) were macerated with n-hexane at room temperature for $48 \mathrm{~h}$..The solvent was removed under reduced pressure and the oil was kept in the fridge at $4{ }^{\circ} \mathrm{C}$ for further manipulation.

\section{Esterification of oil:-}

A Methanolic solution of sodium hydroxide was prepared by dissolving (2g) of sodium hydroxide in $100 \mathrm{ml}$ methanol. A stock solution of methanolic sulphuric acid was prepared by mixing $(1 \mathrm{ml})$ of concentrated sulphuric acid with $(99 \mathrm{ml})$ methanol.

The oil $(2 \mathrm{ml})$ was placed in a test tube and $(7 \mathrm{ml})$ of alcoholic sodium hydroxide were added followed by $(7 \mathrm{ml})$ of alcoholic sulphuric acid. The tube was stoppered and shaked vigorously for five minutes and then left overnight. $(2 \mathrm{ml})$ of supersaturated sodium chloride were added, then $(2 \mathrm{ml})$ of $\mathrm{n}$ - hexane were added and the tube was

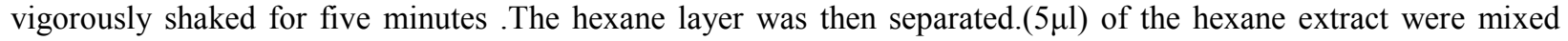
with $5 \mathrm{ml}$ diethyl ether. The solution was filtered and the filtrate $(1 \mu \mathrm{l})$ was injected in the GC-MS vial.

\section{GC-MS analysis:-}

Cyperus esculentus fixed oil was analyzed by gas chromatography - mass spectrometry. A Shimadzo GC-MSQP2010 Ultra instrument with a RTX-5MS column (30m,length; $0.25 \mathrm{~mm}$ diameter ; $0.25 \mu \mathrm{m}$, thickness)was used. Helium (purity; $99.99 \%$ ) was used as carrier gas. Oven temperature program is given in Table 2, while other chromatographic conditions are depicted in Table 3.

Table 2:- Oven temperature program

\begin{tabular}{|l|l|l|}
\hline Rate & Temperature $(\mathrm{C})$ & Hold time $\left(\mathrm{mim}^{-1}\right)$ \\
\hline- & 60.0 & 0.00 \\
\hline 10.00 & 300.0 & 0.00 \\
\hline
\end{tabular}


Table 3:- Chromatographic conditions

\begin{tabular}{|l|l|}
\hline Column oven temperature & $1300.0^{\circ} \mathrm{C}$ \\
Injection temperature & $280.0{ }^{\circ} \mathrm{C}$ \\
Injection mode & Split \\
Flow control mode & Linear velocity \\
Pressure & $93.1 \mathrm{KPa}$ \\
Total flow & $50.0 \mathrm{ml} / \mathrm{min}$ \\
Column flow & $1.50 \mathrm{ml} / \mathrm{sec}$ \\
Linear velocity. & $44.7 \mathrm{~cm} / \mathrm{sec}$ \\
Purge flow & $3.0 \mathrm{ml} / \mathrm{min}$. \\
Spilt ratio & -1.0 \\
\hline
\end{tabular}

\section{Antimicrobial assay:-}

Preparation of bacterial suspensions:-

One $\mathrm{ml}$ aliquots of 24 hours broth culture of the test organisms were aseptically distributed onto nutrient agar slopes and incubated at $37^{\circ} \mathrm{C}$ for 24 hours. The bacterial growth was harvested and washed off with sterile normal saline, and finally suspended in $(100 \mathrm{ml})$ of normal saline to produce a suspension containing about $108-109$ colony forming units per $\mathrm{ml}$. The suspension was stored in the refrigerator at $4^{\circ} \mathrm{C}$ until used. The average number of viable organism per $\mathrm{ml}$ of the stock suspension was determined by means of the surface viable counting technique.

Serial dilutions of the stock suspension were made in sterile normal saline in tubes and one drop volumes (0.02 ml) of the appropriate dilutions were transferred by adjustable volume micropipette onto the surface of dried nutrient agar plates. The plates were allowed to stand for two hours at room temperature for the drop to dry, and then incubated at $37^{\circ} \mathrm{C}$ for 24 hours.

\section{Preparation of fungal suspensions:-}

Fungal cultures were maintained on dextrose agar incubated at $25^{\circ} \mathrm{C}$ for four days. The fungal growth was harvested and washed with sterile normal saline, and the suspension was stored in the refrigerator until used.

\section{Testing for antibacterial activity:-}

The cup-plate agar diffusion method was adopted, with some minor modifications, to assess the antibacterial activity. $(2 \mathrm{ml})$ of the standardized bacterial stock suspension were mixed with $(200 \mathrm{ml})$ of sterile molten nutrient agar which was maintained at $45^{\circ} \mathrm{C}$ in a water bath. $(20 \mathrm{ml})$ Aliquots of the incubated nutrient agar were distributed into sterile Petri dishes. The agar was left to settle and in each of these plates which were divided into two halves, two cups in each half (10 mm in diameter) were cut using sterile cork borer (No 4), each one of the halves was designed for one of the test solutions. Separate Petri dishes were designed for standard antibacterial chemotherapeutics (ampicillin and gentamycin).

The agar discs were removed, alternate cups were filled with ( $0.1 \mathrm{ml})$ samples of each test solution using adjustable volume microtiter pipette and allowed to diffuse at room temperature for two hours. The plates were then incubated in the upright position at $37^{\circ} \mathrm{C}$ for 24 hours.

The above procedure was repeated for different concentrations of the test solutions and the standard chemotherapeutics. After incubation, the diameters of the resultant growth inhibition zones were measured in triplicates and averaged.

\section{Results and Discussion:-}

\section{GC-MS analysis of Cyperus esculentus fixed oil:-}

GC-MS analysis of Cyperus esculentus oil was conducted and the constituents were identified by comparison with the MS library (NIST) and further confirmed by interpreting the observed fragmentation pattern. Comparison with the database on MS library gave about $90-95 \%$ match.

\section{Constituents of oil:-}

The GC-MS spectrum of the studied oil revealed the presence of 21 components(Table 4).The typical total ion chromatograms (TIC) is displayed in Fig.1. 


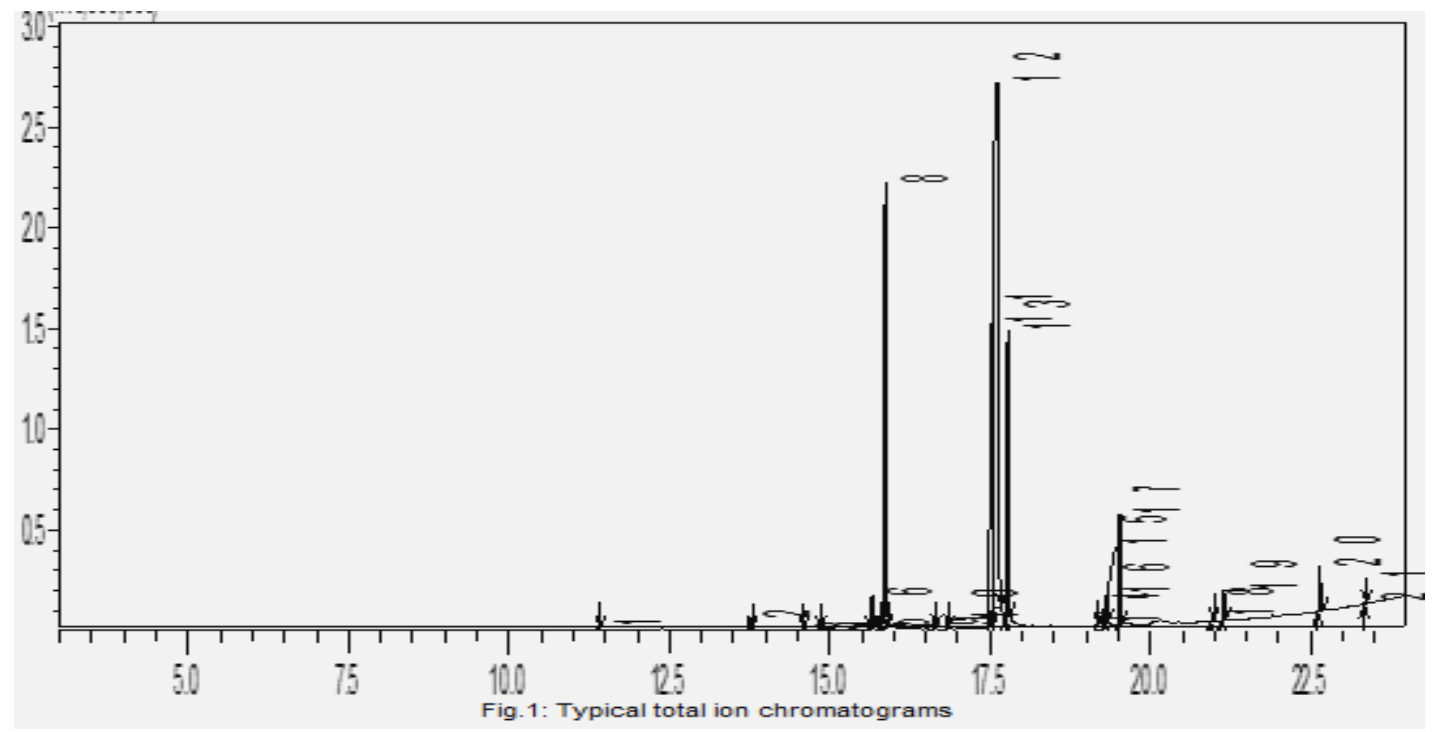

Table 4:- Contituents of Cyperus esculentus oil

\begin{tabular}{|c|c|c|c|c|}
\hline PeakH & R.Time & Area & Area\% & Name \\
\hline 1 & $11.3 \%$ & 276131 & 0.10 & Butylated Hydroxytoluene \\
\hline 2 & 13.747 & 1040707 & 0.38 & Methyl tetradecanoate \\
\hline 3 & 14.559 & 25275 & 0.01 & 6-0ctadecenoic acid, methyl cter \\
\hline 4 & 14,822 & 93781 & 0.03 & Pentadecanoic acid, methyl ester \\
\hline 5 & 15.614 & 153749 & 0.06 & Methyl hexadec-9-enoate \\
\hline 6 & 15.658 & 2544921 & 0.92 & 9-Hexadecenoic acid, methyl ester, (Z)- \\
\hline 7 & 15.731 & 94133 & 0.03 & cis-10-Nonadecenoic acid, methyl ster \\
\hline 8 & 15,868 & 53170840 & 19.27 & Hexadecanoic acid, methyl ester \\
\hline 9 & 16,621 & 388831 & 0.14 & cis-10-Heptadecenoic acid, methyl cter \\
\hline 10 & 16.827 & 726176 & 0.26 & Heptadecanoic acid, methyl eter \\
\hline II & 17.518 & 37587908 & 13.62 & 9,12-0etadecadienoic acid (Z,Z), methyle \\
\hline 12 & 17.613 & 127589980 & 46.24 & 9.0ctadecenoic acid (Z), methyl coter \\
\hline 13 & 17.776 & 30023371 & 10.88 & Methyl stearate \\
\hline 14 & 19.159 & 161246 & 0.06 & 10,13-Eicosadicnoic acid, methyl ester \\
\hline 15 & 19.282 & 1688801 & 0.61 & Oxiraneoctanoic acid, 3-octyl, methyl este \\
\hline 16 & 19,322 & 2190882 & 0.79 & 11-Eicosenoic acid, methyl ester \\
\hline 17 & 19.519 & 10162898 & 3.68 & Methyl 18-methylnonadecanoate \\
\hline 18 & 20,963 & 342486 & 0.12 & 13-Docosenoic acid, methyl ester \\
\hline 19 & 21.137 & 2625595 & 0.95 & Methyl 20-methy-heneicosanoate \\
\hline 20 & 22.639 & 4693698 & 1.70 & Tetracosanoic acid, methyl ester \\
\hline 21 & 23333 & 326153 & 0.12 & Methyl 23-methyl-tetracosanoate \\
\hline & & 275907562 & 100,00 & \\
\hline
\end{tabular}


Some important constituents are discussed below:

9-Octadecenoic acid methyl ester(46.24\%):-

The peak at $\mathrm{m} / \mathrm{z}$ 296, which appeared at R.T. 17.613(Fig.2) in total ion chromatogram, corresponds to $\mathrm{M}^{+}\left[\mathrm{C}_{19} \mathrm{H}_{36} \mathrm{O}_{2}\right]^{+}$, while the peak at $\mathrm{m} / \mathrm{z} 266$ accounts for loss of a methoxyl group.

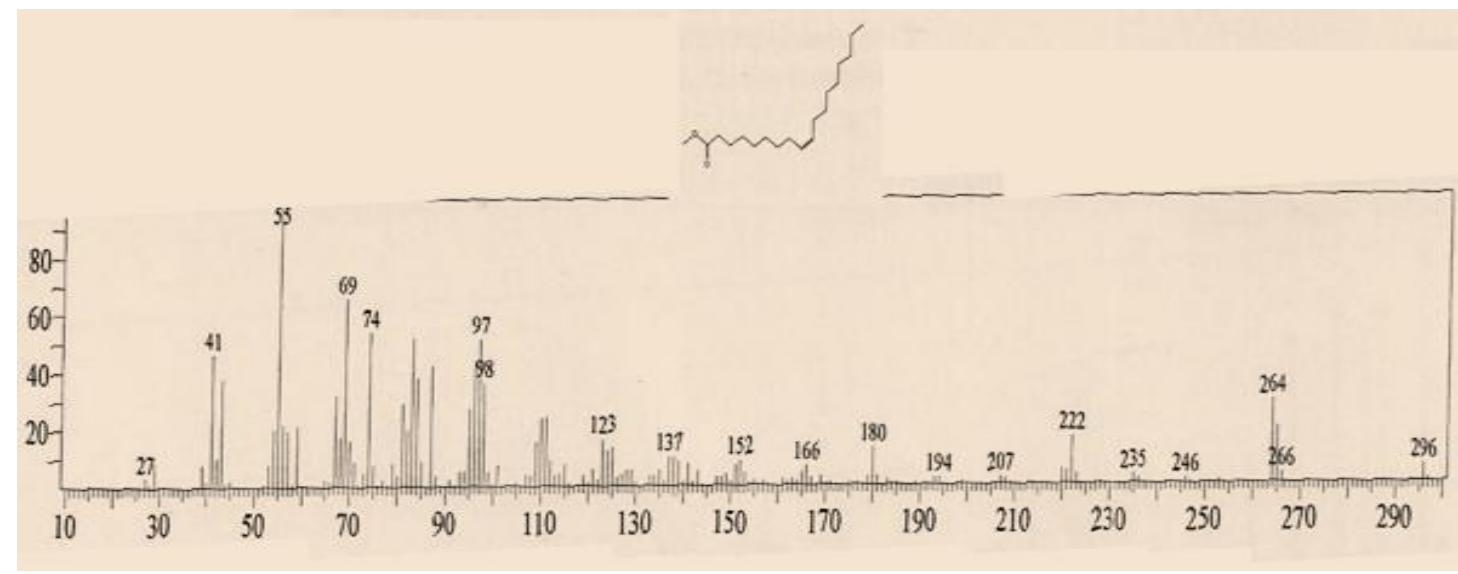

Fig. 2:- Mass spectrum of 9-octadecenoic acid methyl ester.

Oleic acid (9-octadecenoic acid) acid is very common in human diet. The hypotensive potential of olive oil is probably due to this acid (Terese et.al.,2008). This acid finds some applications in soap industry and it is used in small amounts in some pharmaceutical products. It is also used as soldening flux in stained glass work. Oleic acid is employed as emollient(Currasco,2002). It is claimed that the consumption of oleate in olive oil has been associated with decreased risk of breast cancer(Martin et.al.,1994)

9,12-Octadecadienoic acid methyl ester (13.62\%):-

Fig. 3 shows the EI mass spectrum of 9,12-octadecadienoic acid methyl ester. The peak at m/z294, which appeared at R.T. 17.518 in total ion chromatogram, corresponds to $\mathrm{M}^{+}\left[\mathrm{C}_{19} \mathrm{H}_{34} \mathrm{O}_{2}\right]^{+}$. The peak at $\mathrm{m} / \mathrm{z} 263$ corresponds to loss of a methoxyl function.

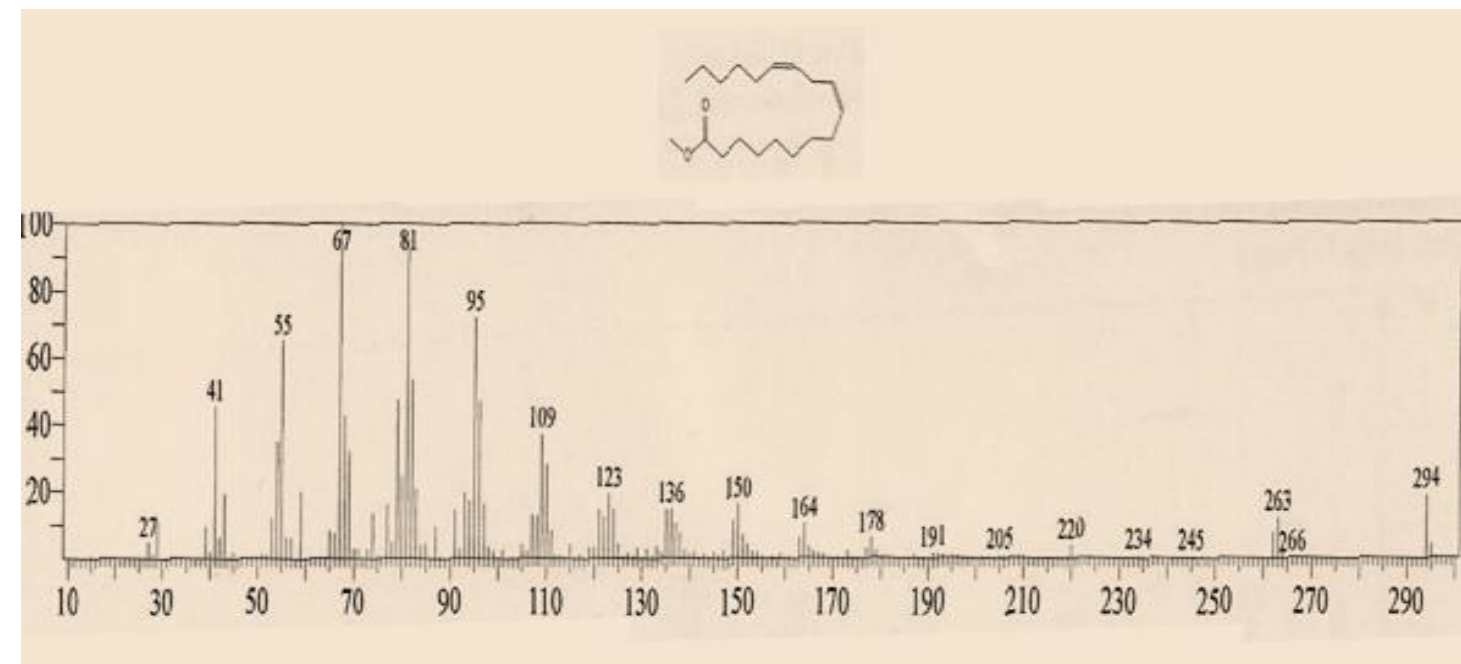

Fig. 3:- Mass spectrum of 9,12-octadecadienoic acid methyl ester.

9,12-Octadecadienoic acid is an essential fatty acid that can not be synthesized by humans and is available through $\operatorname{diet(Burr~et.al.,1930).It~belongs~to~one~of~the~two~families~of~essential~fatty~acids.~It~occurs~in~lipids~of~cell~}$ membrane and is used in the biosynthesis of arachidonic acid. It is converted enzymatically into mono-hydroxy 
products which are subsequently oxidized by some enzymes to keto metabolites..Deficiency of linolate caused hair loss and poor wound healing in model animals(Cunnane and Anderson,1997; Ruthig and Mecklung-Gill,1999).

\section{Hexadecanoic acid methyl ester(19.27\%):-}

Mass spectrum of hexadecanoic acid methyl ester is depicted in Fig. 4.The peak at m/z 270, which appeared at R.T. 15.868 corresponds to $\mathrm{M}^{+}\left[\mathrm{C}_{17} \mathrm{H}_{34} \mathrm{O}_{2}\right]^{+}$while the peak at $\mathrm{m} / \mathrm{z} 239$ is attributed to loss of a methoxyl group.

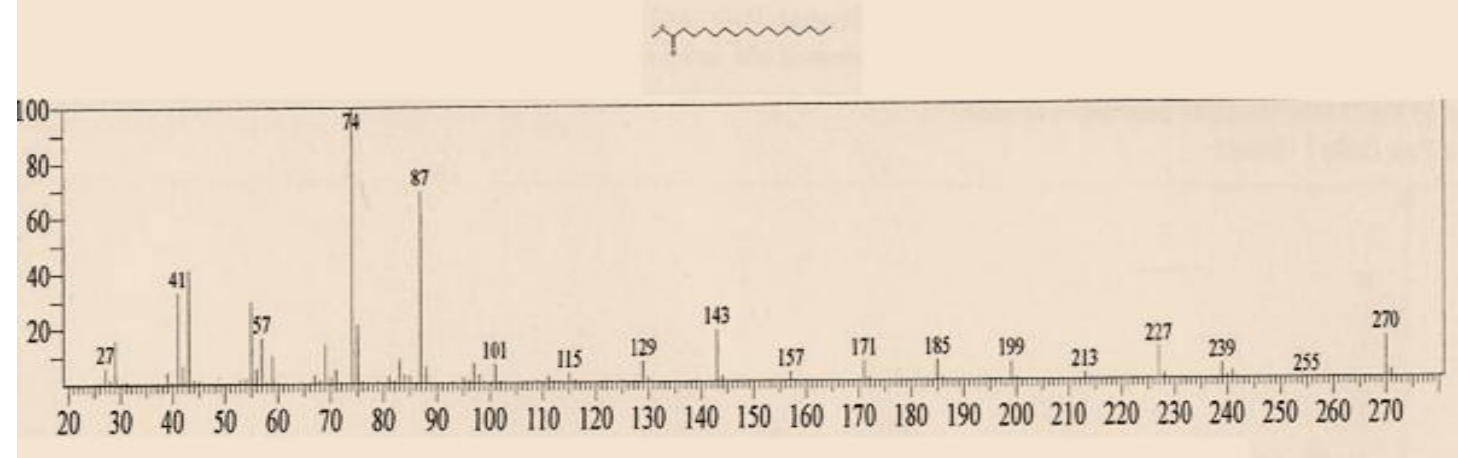

Fig. 4:- Mass spectrum of hexadecanoic acid methyl ester.

Hexadecanoic acid (palmitic acid) is a saturated fatty acid which is very common in plants. It is produced first during the synthesis of fatty acids (Gunstone et.al.,2007) and is considered as precursor of long-chain fatty acids. Palmitic acid is a major lipid component of human breast milk(Kingsbury et.al.,1961; Jensen et.al.,1978). The acid finds applications in soaps and cosmetics industries. It is also used in food industry .

\section{Methyl stearate(10.88\%):-}

Mass spectrum of methyl stearate is shown in Fig. 5.The peak at $\mathrm{m} / \mathrm{z} 298$, which appeared at R.T. 17.776 corresponds to $\mathrm{M}^{+}\left[\mathrm{C}_{19} \mathrm{H}_{38} \mathrm{O}_{2}\right]^{+}$. The peak at $\mathrm{m} / \mathrm{z} 267$ corresponds to loss of a methoxyl function.

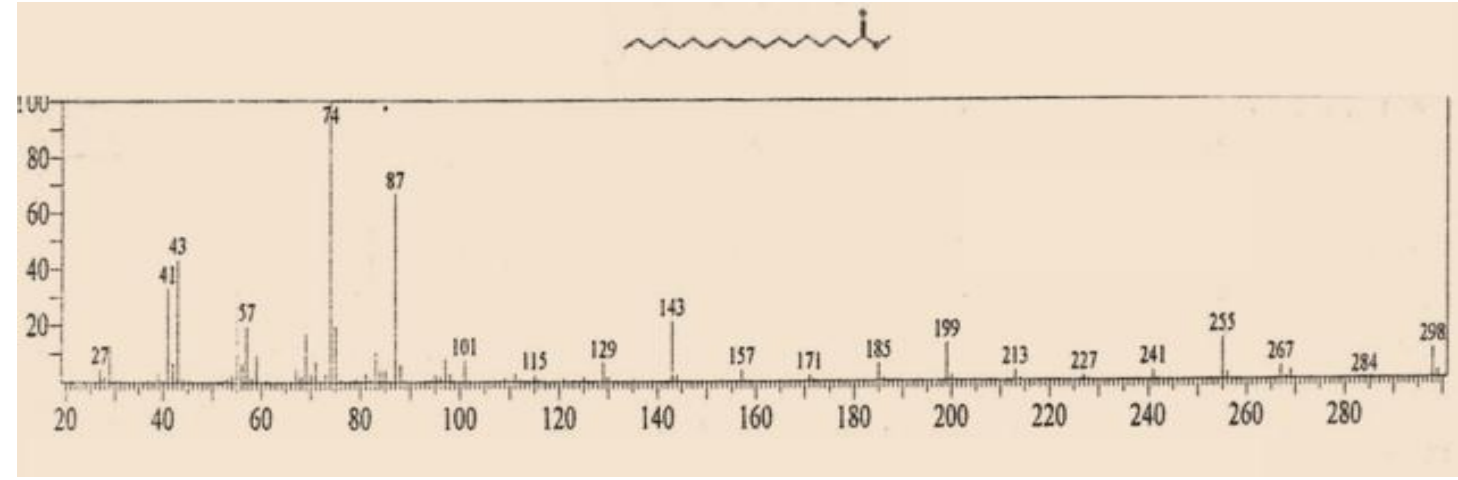

Fig. 5:- Mass spectrum of methyl stearate.

\section{Antibacterial activity:-}

In cup plate agar diffusion assay, the oil was screened for antimicrobial activity against six standard human pathogens. The average of the diameters of the growth of inhibition zones are depicted in Table (5). The results were interpreted in commonly used terms $(<9 \mathrm{~mm}$ : inative;9-12mm:partially active; $13-18 \mathrm{~mm}$ : active; $>18 \mathrm{~mm}$ :very active) .Tables (6) and (7) represent the antimicrobial activity of standard antibacterial and antifungal chemotherapeutic agents against standard bacteria and fungi respectively.

Table 5:- Antibacterial activity of Cyperus esculentus oil

\begin{tabular}{|l|c|l|l|l|l|l|l|}
\hline Type & Conc.(mg/ml) & Sa & Bs & Ec & Ps & Ca & An \\
\hline Oil & 100 & 12 & 8 & - & - & 19 & 8 \\
\hline
\end{tabular}


Table 6:- Antibacterial activity of standard chemotherapeutic agents

\begin{tabular}{|c|c|c|c|c|c|}
\hline Drug & Conc.(mg/ml) & Bs & Sa & Ec & Ps \\
\hline Ampicilin & 40 & 15 & 30 & - & - \\
& 20 & 14 & 25 & - & - \\
& 10 & 11 & 15 & - & - \\
\hline Gentamycin & 40 & 25 & 19 & 22 & 21 \\
& 20 & 22 & 18 & 18 & 15 \\
& 10 & 17 & 14 & 15 & 12 \\
\hline
\end{tabular}

Table 7:- Antifungal activity of standard chemotherapeutic agent

\begin{tabular}{|l|c|l|l|}
\hline Drug & Conc. $(\mathrm{mg} / \mathrm{ml})$ & An & Ca \\
\hline Clotrimazole & 30 & 22 & 38 \\
& 15 & 17 & 31 \\
& 7.5 & 16 & 29 \\
\hline
\end{tabular}

Sa.: Staphylococcus aureus

Ec.: Escherichia coli

Pa.: Pseudomonas aeruginosa

An.: Aspergillus niger

Ca.: Candida albicans

Bs.: Bacillus subtilis

The oil was partially active against Staphylococcus aureus, but it exhibited significant activity against the fungus: Candida albicans.

\section{References:-}

1. Anderson, J.W., Smith, B.M., Gustafson, N.J. (1994), Amer. J. Clinical Nutr., 59, 1242.

2. Borges, O, Goncalves, B., Sgeoeiro, L., Correia, P., Silva, A. (2008), Food Chem., 106,976.

3. Burr,G.O.,Burr,M.,Miller,E.(1930),J.Biol.Chem.,86,587.

4. Carresco.F.(2002), "Ingradients de Cosmeticos" ,Dictionario De Ingredientes,4 $4^{\text {th }}$ ed.,P428 : ISBN 978-84-6134979-1.

5. Chevallier A (1996), "The Encyclopedia of Medicinal Plants", Dorling Kindersley, London; ISBN: 9- 980751303148.

6. Cunnane,S., Anderson,M,(1997), J.Lipid Res.,38,805.

7. D.e Abreu Matos, F.J., Cavalcanti, F.S., Parente, J.P.( 2008), Revista Ciencia Agronomica, 39(1),124.

8. Garg, D.K., Bendixen,L.E. and Anderson,S.R. (1967), Weeds,15,124.

9. Guthery, F.S. (1976), Foods and Feeding Habitat of Cranes in Southern Texas, pages 117-125: In J.C. Lewis( ed.) "1975 Proc. Int. Crane Workshop".

10. Gunstone,F.D.,John,L.,Albert,J.(2007) "The Lipid Handbook", ${ }^{\text {rd }}$ ed., Boca Raton, CRC Press.

11. Jensen,R.G.,Hagerty,M.M. and Mc-Mahon ,K.E.(1978), Am.J.Clin.Nut.,31(6),990.

12. Kingsbury,K.J.,Paul,S.,Crossley,A.,Morgan,D.(1961),Biochemical Journal,78,541.

13. Martin,M.,Jose,M.,Lydia,B.,Jose,R.,Rodinguez,A.,F.,Fermandez,R.,Juan,C.,Maisonneuve,P.(1994),Intenationa l Journal of Cancer, 58(6),774

14. Mason, D. : Tiger Nuts; In: http://www.nvsuk.org.uk/growing show_vegetables_1/tiger-nut.php 2005.

15. McAfee, W.L.(1939) "Wildfowl Food Plants: Their Value, Propagation, and Management, Collegiate Press Inc.,United States , $141 \mathrm{pp}$

16. Oderinde, R.A., Tairu, O.A. (1988), Food Chem., 28,233.

17. Ruthig,D.J., Meckling-Gill,K.A.(1999), Journal of Nutrition,129(10),179.

18. Terese,S.,Barcelo,G.,Benet,M.,Alvarez,R.,Bressani,R.,Halver,J.E.,Escriba,P.V.(2008) In : Proceedings of the Natural Academy of Science,105(37),13811. 